\title{
Comparison of Predicted and Measured Turbine Vane Rough Surface Heat Transfer
}

R.J. Boyle, C.M. Spuckler, and B.L. Lucci Glenn Research Center, Cleveland, Ohio 
The NASA STI Program Office ... in Profile

Since its founding, NASA has been dedicated to the advancement of aeronautics and space science. The NASA Scientific and Technical Information (STI) Program Office plays a key part in helping NASA maintain this important role.

The NASA STI Program Office is operated by Langley Research Center, the Lead Center for NASA's scientific and technical information. The NASA STI Program Office provides access to the NASA STI Database, the largest collection of aeronautical and space science STI in the world. The Program Office is also NASA's institutional mechanism for disseminating the results of its research and development activities. These results are published by NASA in the NASA STI Report Series, which includes the following report types:

- TECHNICAL PUBLICATION. Reports of completed research or a major significant phase of research that present the results of NASA programs and include extensive data or theoretical analysis. Includes compilations of significant scientific and technical data and information deemed to be of continuing reference value. NASA's counterpart of peerreviewed formal professional papers but has less stringent limitations on manuscript length and extent of graphic presentations.

- TECHNICAL MEMORANDUM. Scientific and technical findings that are preliminary or of specialized interest, e.g., quick release reports, working papers, and bibliographies that contain minimal annotation. Does not contain extensive analysis.

- CONTRACTOR REPORT. Scientific and technical findings by NASA-sponsored contractors and grantees.
- CONFERENCE PUBLICATION. Collected papers from scientific and technical conferences, symposia, seminars, or other meetings sponsored or cosponsored by NASA.

- SPECIAL PUBLICATION. Scientific, technical, or historical information from NASA programs, projects, and missions, often concerned with subjects having substantial public interest.

- TECHNICAL TRANSLATION. Englishlanguage translations of foreign scientific and technical material pertinent to NASA's mission.

Specialized services that complement the STI Program Office's diverse offerings include creating custom thesauri, building customized data bases, organizing and publishing research results ... . even providing videos.

For more information about the NASA STI Program Office, see the following:

- Access the NASA STI Program Home Page at http://www.sti.nasa.gov

- E-mail your question via the Internet to help@sti.nasa.gov

- Fax your question to the NASA Access Help Desk at 301-621-0134

- Telephone the NASA Access Help Desk at 301-621-0390

- Write to:

NASA Access Help Desk

NASA Center for AeroSpace Information 7121 Standard Drive

Hanover, MD 21076 
NASA/TM-2000-210219

ASME 2000-GT-0217

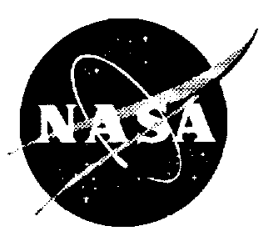

\section{Comparison of Predicted and Measured Turbine Vane Rough Surface Heat Transfer}

R.J. Boyle, C.M. Spuckler, and B.L. Lucci

Glenn Research Center, Cleveland, Ohio

Prepared for the

45th International Gas Turbine and Aeroengine Technical Congress

sponsored by the American Society of Mechanical Engineers

Munich, Germany, May 8-11, 2000

National Aeronautics and

Space Administration

Glenn Research Center 
Available from

NASA Center for Aerospace Information

National Technical Information Service 5285 Port Royal Road Springfield, VA 22100

Hanover, MD 21076

Price Code: A03

Price Code: A03

Available electronically at http://gltrs.grc.nasa.gov/GLTRS 


\title{
COMPARISON OF PREDICTED AND MEASURED TURBINE VANE ROUGH SURFACE HEAT TRANSFER
}

\author{
R.J. Boyle, C.M. Spuckler, and B.L. Lucci \\ National Aeronautics and Space Administration \\ Glenn Research Center \\ Cleveland, Ohio 44135
}

\begin{abstract}
l'ridiclad turhine vane heat transfer for rough surfaces wa collpared with experimental data for both vane aml ruir. For the vane comparisons, inlet pressure virinl lweween 0.2 and 1 atm., and exit Mach numbrer ranall hetween 0.3 and 0.9 . Thus, while a single ruluh - inface vane was used for the tests, the effectiv. runghurss in wall units varied by more than a fir.tur , f 1,11 ('omparisons were made for both high and l.M fr..ntran turbulence intensities. For the ro1or. cumpurisum were made at two Reynolds numbers

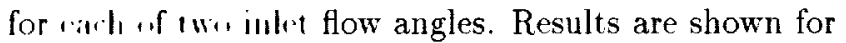
boll, -llm,llam rough rotor blades. Two-dimensional Navi.r.St.h.. l, it transfer predictions were obtained using Il" roll IIV C'Q3D. Results were obtained using botli als. hratir and $k-\omega$ turbulence models. The algelirair Im..l.l incorporated the Cebeci-Chang roughness Im,.l. I Tl, $l \cdot-\omega$ turbulence model accounts for roughı,... in th. houndary condition. Roughness causes turbul.nl Hiw over the vane surface. Even after accountiun fur transition, surface roughness significantly increased le.ill Iransfer compared to a smooth surface. The $k$ - - resulıs agreed better with the data than the C'ruci-chang model. The low Reynolds number $k-w$ model did not accurately account for roughness at low freestrean turbulence levels. The high Reynolds number version of this model was more suitable at low freestream turbulence levels.
\end{abstract}

\section{Nomenclature}

$$
\begin{array}{ll}
A^{+} & - \text {Near wall damping coefficient } \\
C_{f} / 2 & - \text { Friction factor } \\
C_{p} & - \text { Pressure coefficient } \\
C_{\mathrm{x}} & - \text { Axial chord }
\end{array}
$$
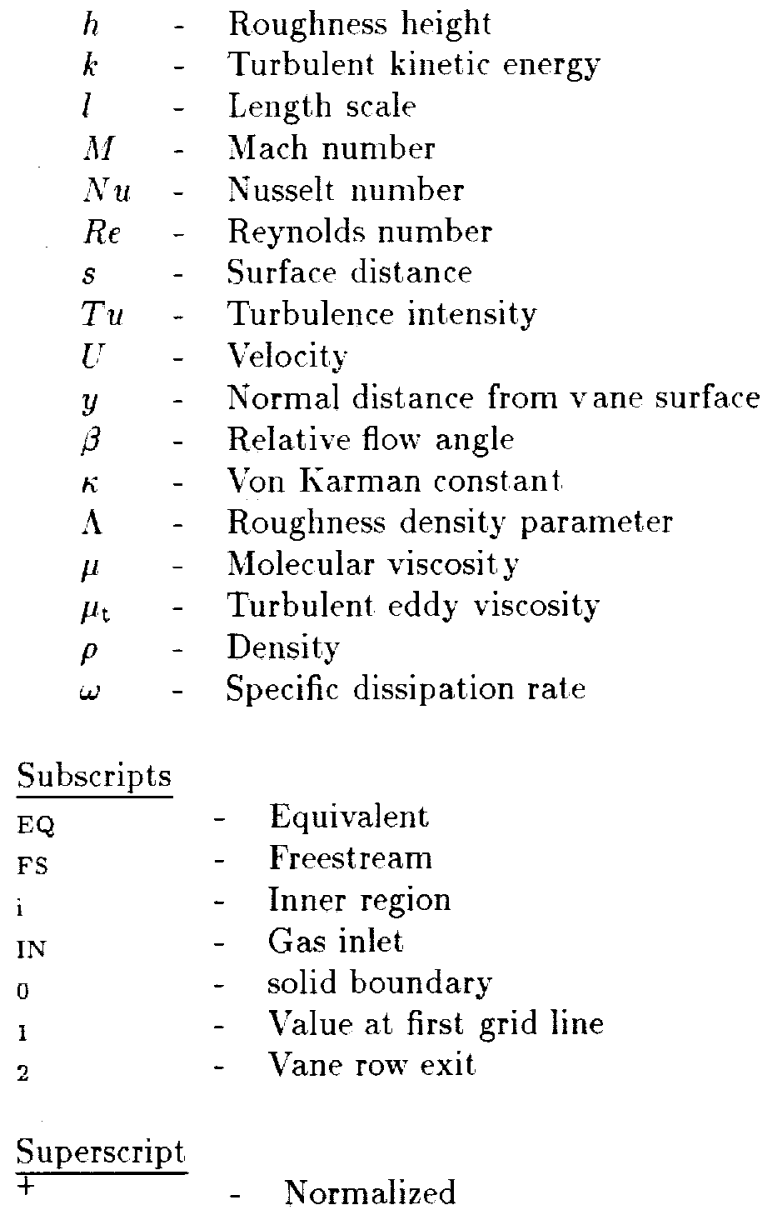

\section{INTR ODUCTION}

The ability to predict the effects of surface roughness on both turbine aerodynamics and heat transfer is important. Several researchers have reported decreases in turbine efficiency of up to several points due to 
surface roughness. Among these are Kind et al.(1998), Boynton et al.(1992), and Bammert and Stanstede $(1972,1976)$. In addition to causing a decrease in aerodynamic efficiency, surface roughness can significantly modify turbine blade surface heat transfer. Dunn et al.(1994), Blair(1994), Tarada and Suzuki(1993), and Abuaf et al.(1997) among others showed the effects of surface roughness on turbine blade heat transfer. The degree to which surface roughness affected the surface heat transfer varied among the investigators. Accurate heat transfer predictions for rough surface turbine blades are important in accurately predicting turbine blade life. Surface roughness can cause a laminar boundary layer to become turbulent, and increase the heat transfer coefficient over that for a smooth blade. The increased heat transfer coefficien $t$ may or may not increase the heat load to the blade. If the surface roughness is caused by deposition of low conductivity material, the heat load may decrease. However, if the roughness is caused by erosion the heat load increases at the same time the blade strength is decreased. The present work is focused on verifying predictions for the external heat transfer coefficient, and does not address the effect on blade temperature.

Several investigators have analyzed the heat transfer to rough surface blades. One approach, advocated by Taylor et al.(1985), and utilized by Tolpadi and Crawford(1998), and Tarada(1990) is to model the roughness as geometrical elemen ts attached to a smooth surface. To account for the blockage of these elements the equations of continuity, momentum and energy are modified in the near wall region. Another approach is to assume the roughness affects the flow in a way similar to sand grain roughness. In this approach the turbulent eddy viscosity is increased based on correlations for sand grain roughness. Here the physical roughness is related to equivalent sand grain roughness by empirical correlations. For algebraic turbulence models Cebeci and Chang(1978) recommended a procedure to modify the turbulent viscasity for sand grain roughness. Their model was used by Boyle and Civinskas(1991) to predict heat transfer for rough turbine blades. Wilco $\mathrm{x}(1994)$ accounted for surface roughness by modifying the boundary condition in the $k-\omega$ turbulence model. It is the latter approach that is utilized in the work reported herein. This approach is simpler than the one advocated by Taylor et al.(1985), and it was felt that the variation in roughness properties, even within a single roughness trace, was large enough to discourage modeling the roughness as a series of repeated geometric elements.
The work reported herein used the data obtained by Boyle et al.(2000) to identify an appropriate means of predicting the effects of surface roughness on turbine blade heat transfer. It is felt that the approach identified would also be a suitable candidate for the verification of turbine aerodynamic performance. In addition, comparisons are shown with the midspan rotor blade heat transfer presented by Blair(1994). This is done to show that the conclusions drawn from the comparisons with the data of Boyle et al.(2000), also apply for the comparisons with the data of Blair(1994).

\section{DESCRIPTION of ANALYSIS}

A two-dimensional Navier-Stokes analysis was used to predict the effect of surface roughness on vane surface heat transfer. The computer code used was the quasithree dimensional analysis described by Chima(1987) and by Chima an Yokota(1988). For the test configuration analyzed there were no three-dimensional effects expected. The analysis developed by Chima(1987), and Chima and Yokota(1988) is a thin layer Navier-Stokes formulation, that achieves a steady-state solution using a Runge-Kutta time marching approach. Implicit residual smoothing is also used.

Two algebraic models, Baldwin and Lomax(1978) and Chima et al.(1993), and one two-equation $k-\omega$ turbulence model, Chima(1996), are incorporated in to the code. The $k-\omega$ model has both high and low Reynolds number formulations. The Cebeci-Chang(1978) roughness model is in both algebraic turbulence models. Results are given for only one of the algebraic models, Chima et al.(1993). The effect of surface roughness was found to be relatively the same for both.

C-type grids were used, and were generated using the method of Arnone et al.(1992). Grid parameters, especially the near wall spacing, were varied to ensure that the presented results were obtained with grids of sufficient resolution. A typical grid was $257 \times 49$ with a maximum near wall normalized grid spacing less than one. The turbulence models had differences in heat transfer sensitivity to near wall grid spacing. This is discussed in the comparison of results. The heat transfer coefficients are determined by the fluid temperature gradient at the wall

Equivalent roughness height. For the algebraic and twoequation turbulence models roughness enters into the analysis by means of an equivalent roughness height, $h_{\mathrm{EQ}}$. The equivalent roughness height accounts for variations in the spatial distribution of roughness. Several different correlations have been proposed to obtain the $h_{\mathrm{EQ}}$ from the roughness. These correlations require that roughness be characterized as having a geometric 


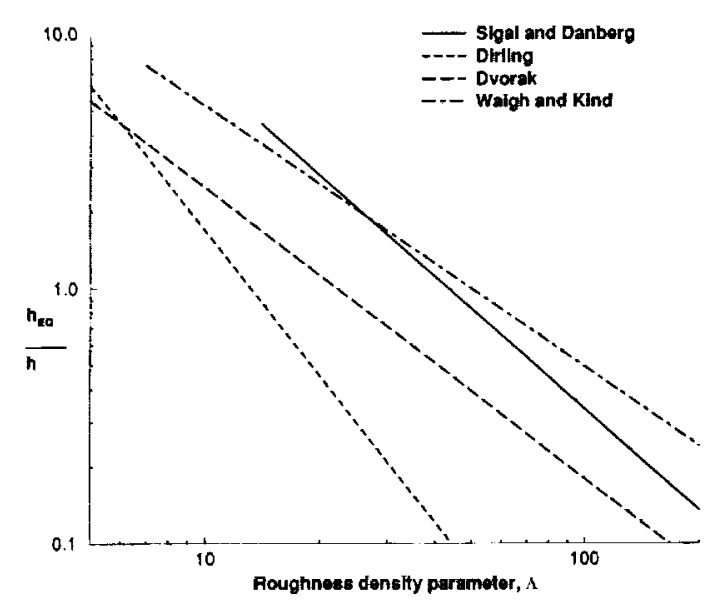

Fig. 1 Comparieons of equivalont height ratlo conslations.

shape. Figure 1 compares different correlations for obtaining the equivalent roughness height as a function of the roughness density parameter, $\Lambda$. These correlations were developed from data using deterministic, and not random, roughness. This figure is primarily illustrative. Direct comparisons cannot be made among the different correlations for roughness height because each uses a different definition for $\Lambda$. However, it does illustrate the large range of equivalent height ratios predicted by different correlations available in the literature.

Six roughness traces were obtained from the vane surface tested by Boyle et al.(2000). Figure 2 shows a typical roughness trace. From each trace the RMS height, $h_{\mathrm{RMS}}$, was calculated The average value was $111 \mu \mathrm{m}$, and the one sigma variation among the six traces was $\pm 18 \mu \mathrm{m}$. The profiles in the traces were then analyzed assuming the roughness was either cones or hemispheres. Table I gives the equivalent height ratios obtained using the different correlations for each of the six traces. If each roughness trace had a different value of $h_{\mathrm{RMS}}$, but all were geometrically similar, there would be no variation in $h_{\mathrm{EQ}} / h_{\mathrm{RMS}}$. Results are shown for two model geometries; cones and hemispheres. Results are also shown for two assumptions as to what constitutes a peak in the roughness profile. In one definition, a peak is given as a change in the profile slope which occurs above the mean. In the other definition, a peak has to exceed the mean by $h_{\mathrm{RMS}}$. The second assumption was made because it was felt that peaks in the shadow of higher peaks might not be as influential with respect to surface roughness effects. Compared to the first assumption, the second assumption leads to fewer, but taller peaks, spaced further apart. The results in Table I show that the second assumption results in only a small decrease of about 10 to $20 \%$ in the equivalent height ratio, $h_{\mathrm{EQ}} / h_{\mathrm{RMS}}$.

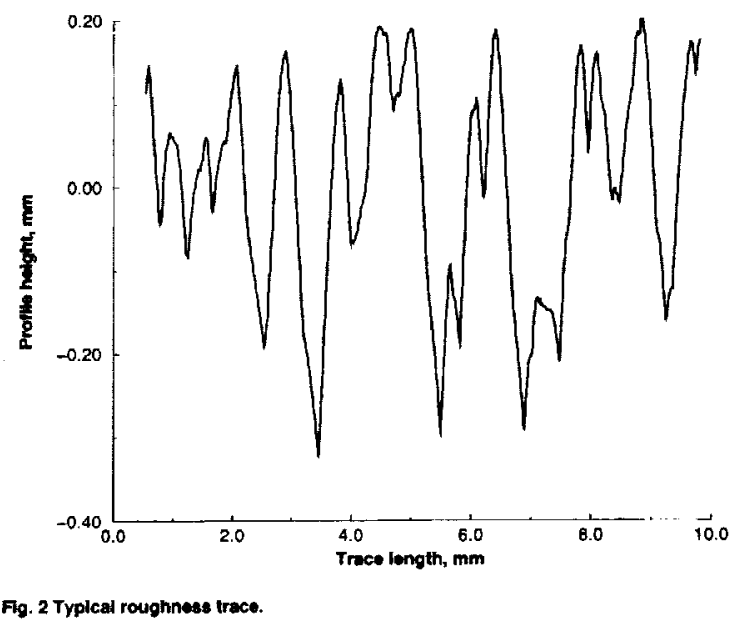

Even after accounting for different definitions of $A$, there is a significant variation for the equivalent height ratio among the correlations. When the roughness is modeled as cones, the Sigal and Danberg(1990) correlation gives an equivalent height ratio about half that of the other correlations. For conical models there is less variation among the Dvorak(1969), Dirling(1973), and W aigh and Kind(1998) correlations. For hemispherical models the Dvorak, and $W$ aigh and Kind correlations are significantly higher than the other two correlations. In this table there are two values of the equivalent height ratio for each model geometry and trace. The roughness traces were analyzed for skewness and kurtosis. The negative value of kurtosis indicates a bumpy rather than spiky profile, Dagnall(1986). This would favor hemispheres over cones as the model geometry to determine the equivalent height. However, when roughness elements are modeled as hemispheres, rather than cones, the slope of the roughness is not considered. When modeled as hemispheres, the height and radius are equal. The average slope was calculated to be greater than 45 degrees. Also, hemispheres have greater frontal area than cones. For these reasons it is felt that conical elements were appropriate for determining the equivalent roughness height. The average equivalent height ratio, $h_{\mathrm{EQ}} / h_{\mathrm{RMS}}$, was 2.1 for the widely spaced conical roughness elements.

Even though a single roughness height is used in the analysis, the normalized roughness height, $h^{+}$varies around the vane in accordance with the local flow conditions.

$$
h^{+}=h_{\mathrm{EQ}} U_{\mathrm{FS}} \rho \sqrt{C_{f} / 2} / \mu
$$

The freestream velocity, $U_{\mathrm{FS}}$, and $\rho$ are obtained from pressure distribution using the isentropic relationships. When $C_{f} / 2$ is zero, $h^{+}$is zero, independent of the actual roughness height. 
Table I. Equivalent height ratio, $h_{\mathrm{EQ}} / h$

\begin{tabular}{|c|c|c|c|c|c|c|c|c|c|}
\hline & \multicolumn{9}{|c|}{ Equivalent Height Roughness Model } \\
\hline \multirow[t]{3}{*}{ Trace } & $h_{\mathrm{RMS}} \mathrm{mm}$ & Sigal & \& Danberg & & Drorak & & Dirling & Wa & gh \& kind \\
\hline & & \multicolumn{8}{|c|}{$h_{\text {PEAK }}>0-$ Cone Model } \\
\hline & & $\Lambda$ & $h_{\mathrm{EQ}} / h_{\mathrm{RMS}}$ & $\Lambda$ & $h_{\mathrm{EQ}} / h_{\mathrm{RMS}}$ & $\Lambda$ & $h_{\mathrm{EQ}} / h_{\mathrm{RMS}}$ & $\Lambda$ & $h_{\mathrm{EQ}} / h_{\mathrm{RMS}}$ \\
\hline 1 & 0.128 & 45.1 & 1.95 & 11.5 & 4.31 & 10.0 & 3.43 & 27.1 & 3.84 \\
\hline 2 & 0.131 & 44.6 & 1.84 & 10.9 & 4.25 & 9.9 & 3.28 & 27.3 & 3.53 \\
\hline 3 & 0.107 & 47.1 & 1.96 & 12.1 & 4.32 & 10.3 & 3.49 & 28.2 & 3.92 \\
\hline 4 & 0.097 & 72.3 & 0.90 & 18.8 & 2.13 & 12.7 & 1.87 & 43.0 & 2.05 \\
\hline 5 & 0.119 & 87.2 & 0.69 & 21.3 & 1.79 & 13.8 & 1.57 & 53.4 & 1.60 \\
\hline 6 & 0.085 & 152.4 & 0.36 & 42.2 & 0.90 & 18.8 & 0.95 & 87.7 & 1.06 \\
\hline \multirow[t]{3}{*}{ Avg. } & 0.111 & & 1.28 & & 2.95 & & 2.43 & & 2.67 \\
\hline & & \multicolumn{8}{|c|}{$h_{\text {PEAK }}>0-$ Hemisphere } \\
\hline & & $\bar{\Lambda}$ & $h_{\mathrm{EQ}} / h_{\mathrm{RMS}}$ & $\Lambda$ & $h_{\mathrm{EQ}} / h_{\mathrm{RMS}}$ & $\Lambda$ & $h_{\mathrm{EQ}} / h_{\mathrm{RMS}}$ & $\bar{\Lambda}$ & $h_{\mathrm{EQ}} / h_{\mathrm{RMS}}$ \\
\hline 1 & 0.128 & 20.0 & 5.65 & 6.6 & 8.12 & 8.1 & 5.14 & 4.9 & 9.28 \\
\hline 2 & 0.131 & 18.1 & 5.99 & 5.9 & 8.46 & 7.7 & 5.25 & 4.4 & 7.15 \\
\hline 3 & 0.107 & 21.3 & 5.56 & 7.0 & 8.07 & 8.3 & 5.16 & 5.2 & 11.05 \\
\hline 4 & 0.097 & 33.2 & 2.51 & 10.9 & 3.93 & 10.4 & 2.74 & 19.5 & 4.63 \\
\hline 5 & 0.119 & 35.4 & 2.25 & 11.7 & 3.56 & 10.8 & 2.51 & 20.7 & 4.22 \\
\hline 6 & 0.085 & 80.7 & 0.84 & 26.6 & 1.52 & 16.3 & 1.26 & 47.3 & 1.99 \\
\hline \multirow[t]{3}{*}{ Avg. } & 0.111 & & 3.80 & & 5.61 & & 3.68 & & 6.39 \\
\hline & & \multicolumn{8}{|c|}{$h_{\text {PEAK }}>h_{\mathrm{RMS}}-$ Cone Model } \\
\hline & & $\Lambda$ & $h_{\mathrm{EQ}} / h_{\mathrm{RMS}}$ & $A$ & $h_{\mathrm{EQ}} / h_{\mathrm{RMS}}$ & $\Lambda$ & $h_{\mathrm{EQ}} / h_{\mathrm{RMS}}$ & $\bar{\Lambda}$ & $h_{\mathrm{EQ}} / h_{\mathrm{RMS}}$ \\
\hline 1 & 0.128 & 68.4 & 1.41 & $1 \overline{7.5}$ & 3.35 & 12.3 & 2.89 & 41.0 & 3.14 \\
\hline 2 & 0.131 & 61.1 & 1.65 & 15.0 & 4.03 & 11.6 & 3.30 & 37.4 & 3.47 \\
\hline 3 & 0.107 & 53.8 & 2.12 & 13.8 & 4.79 & 11.0 & 3.96 & 32.1 & 4.41 \\
\hline 4 & 0.097 & 98.6 & 0.72 & 25.6 & 1.79 & 14.9 & 1.67 & 58.7 & 1.79 \\
\hline 5 & 0.119 & 162.2 & 0.40 & 39.7 & 1.14 & 18.8 & 1.12 & 99.2 & 1.10 \\
\hline 6 & 0.085 & 189.5 & 0.33 & 52.5 & 0.85 & 21.0 & 0.93 & 109.0 & 1.02 \\
\hline \multirow[t]{3}{*}{ Avg. } & 0.111 & & 1.11 & & 2.66 & & 2.31 & & 2.49 \\
\hline & & \multicolumn{8}{|c|}{$h_{\text {PEAK }}>h_{\mathrm{RMS}}-$ Hemisphere } \\
\hline & & $\Lambda$ & $h_{\mathrm{EQ}} / h_{\mathrm{RMS}}$ & $\Lambda$ & $h_{\mathrm{EQ}} / h_{\mathrm{RMS}}$ & $\Lambda$ & $h_{\mathrm{EQ}} / h_{\mathrm{RMS}}$ & $\Lambda$ & $h_{\mathrm{EQ}} / h_{\mathrm{RMS}}$ \\
\hline 1 & 0.128 & 30.4 & 4.10 & 10.0 & 6.32 & 10.0 & 4.33 & 17.8 & 7.37 \\
\hline 2 & 0.131 & 24.8 & 5.37 & 8.2 & 8.01 & 9.0 & 5.28 & 14.6 & 9.11 \\
\hline 3 & 0.107 & 24.5 & 6.02 & 8.0 & 8.94 & 5.9 & 5.86 & 14.2 & 10.15 \\
\hline 4 & 0.097 & 45.3 & 2.05 & 14.9 & 3.31 & 12.2 & 2.44 & 26.5 & 4.04 \\
\hline 5 & 0.119 & 65.8 & 1.29 & 21.7 & 2.27 & 14.7 & 1.80 & 38.6 & 2.89 \\
\hline 6 & 0.085 & 100.4 & 0.76 & 33.1 & 1.43 & 18.1 & 1.23 & 58.9 & 1.91 \\
\hline Avg. & 0.111 & & 3.27 & & 5.05 & & 3.49 & & 5.91 \\
\hline
\end{tabular}

Algebraic turbulence model. The Cebeci-Chang(1978) roughness model increases the mixing length to accoun $t$ for roughness. The distance increment is given by:

$$
\Delta y^{+}=0.9\left(\sqrt{h^{+}}-h^{+} e x p^{-0.167 h^{+}}\right)
$$

and

$$
\Delta y=\Delta y^{+} \mu / U_{\mathrm{FS}} \rho \sqrt{C_{f} / 2}
$$

In the algebraic models the increment in $y$ is only applied in the inner region. The turbulent eddy viscosity in the inner region, $\mu_{\mathrm{t}, \mathrm{i}}$ is given by:

$$
\mu_{\mathrm{t}, \mathrm{i}}=\rho(d U / d y)\left[\kappa(y+\Delta y)\left(1-\exp ^{-\left(y^{+}+\Delta y^{+}\right) / A^{+}}\right)\right]^{2}
$$

When fully turbulent flow is not assumed, the transition model does not account for roughness. There is no mechanism in the analysis to allow for roughness effects when the flow is calculated to be laminar.

$k-\omega$ turbulence model. In this model roughness influences the solution through the boundary condition on $\omega$. At the vane surface

$$
\omega_{0}=\max \left(\omega_{\mathrm{IN}}, \max \left(2500 /\left(h^{+}\right)^{2}, 100 / h^{+}\right) d U / d y\right)
$$

and

$$
\omega_{\mathrm{IN}}=\sqrt{1.5\left(U_{\mathrm{IN}} T u_{\mathrm{IN}}\right)^{2}} / l_{\mathrm{IN}}
$$

At the surface $k_{0}=0$. 
Table II. Summary of test conditions,

\begin{tabular}{|c|c|c|}
\hline & \multicolumn{2}{|c|}{ Ideal Axial chord Re No. $\times 10^{-6}$} \\
\hline$M_{2}$ & Inlet & Exit \\
\hline 0.3 & 0.0055 & 0.041 \\
& 0.0086 & 0.061 \\
& 0.0157 & 0.101 \\
& 0.0278 & 0.202 \\
& 0.0405 & 0.303 \\
\hline 0.7 & 0.0317 & 0.236 \\
& 0.0521 & 0.391 \\
& 0.0792 & 0.590 \\
\hline 0.9 & 0.0307 & 0.240 \\
& 0.0555 & 0.144 \\
& 0.0826 & 0.665 \\
\hline
\end{tabular}

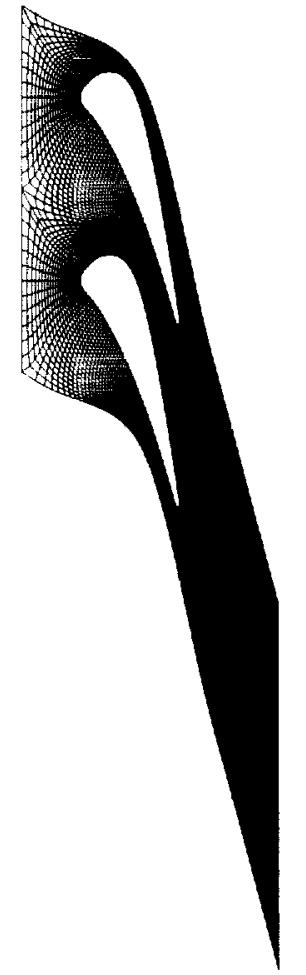

Fig. 3 Computational domaln

The inlet $\omega$ decreases as the inlet turbulence intensity decreases, and as the length scale increases. All of the comparisons with data examined herein had a large inlet length scale when the inlet turbulence was high. At low $T u_{\text {IN }}$ and large $l_{\text {IN }}$ the wall boundary condition on $\omega$ is determined by $h^{+}$. When $\omega_{\text {IN }}$ is small and $h^{+}>25$, $\omega_{0}=100 / h^{+} d U / d y$. When this condition applies flow is likely to be fully rough, where $C_{f} / 2$ is independent of Reynolds number. Increasing $R e$ at a constant Mach number causes $h^{+}$to increase, which results in $\omega_{0}$ decreasing nearly in proportion to $R e$ increasing. Also,

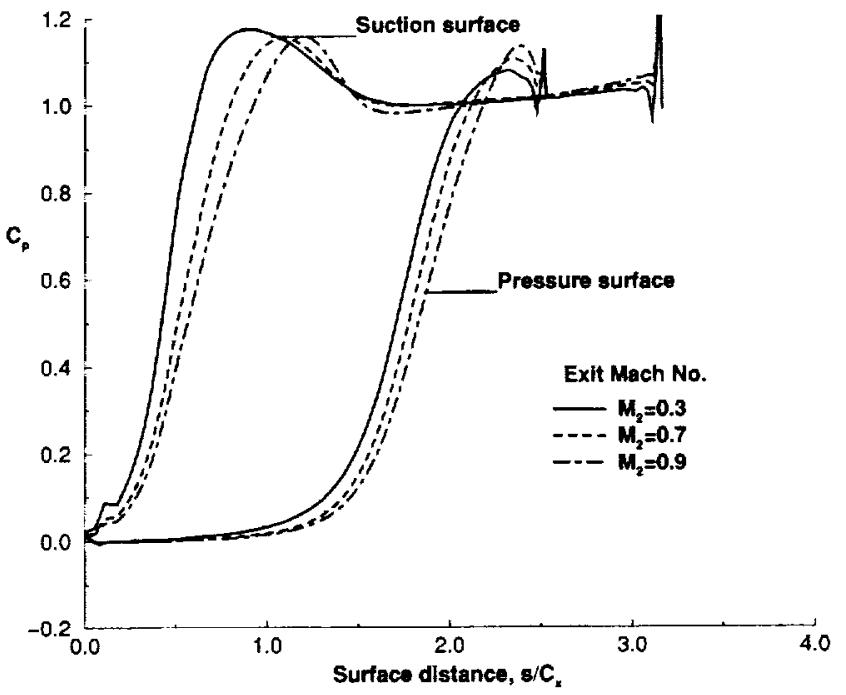

Flg. 4 Predicted pressure coefficient.

if the exit Mach number increases at constant Re, $d U / d y$ increases, and $\omega_{0}$ increases. Increasing vane exit Mach number at constant $R t$ has the same effect on $\omega_{0}$ as decreasing $R \epsilon$ at constant exit Mach number. The difference between the high and low Reynolds number formulations of the $k-\omega$ models is that the low formulation modifies the production and destruction terms by factors which are functions of the turbulent Reynolds number. Details of the implementation of the high and low Reynolds number formulations are given by Chima(1996). For smooth surfaces, the low Reynolds number formulation, denoted as $L k \omega$, is prefered. However, it was found that this formulation predicted transition further downstream than was seen in the data. The high Reynolds formulation, denoted as $\mathrm{Hkw}$, gave transition behavior more consistent with the data.

\section{DISCUSSION of RESUL TS \\ Stator data results}

The range of test conditions is given in Table II. Comparisons are made with data for three or five Reynolds numbers at each of three exit Mach numbers. For each test condition shown in Table II data were obtained at two inlet turbulence levels.

The vane, along with the computational domain is shown in figure 3 . The grid shown in this figure is not the actual grid, since many grid lines have been removed to clarify the figure. The figure shows a vane with 80 degrees of turning.

Figure 4 shows the pressure distribution around the vane at the three exit Mach numbers. The pressure coefficient, $C_{p}$, is the difference between the inlet total pressure and the local static pressure divided by the 

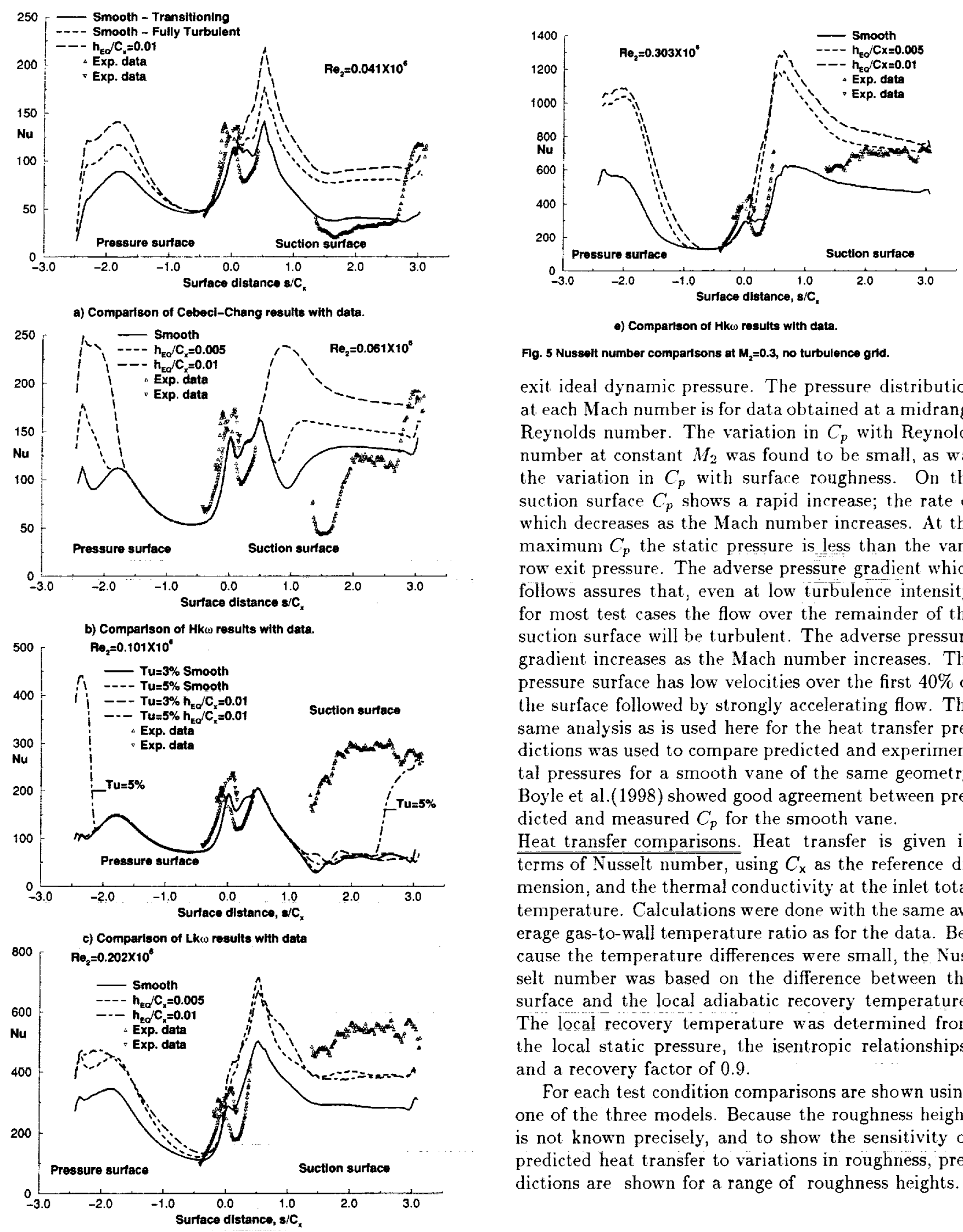

e) Comparison of Hkw results with data.

Fig. 5 Nusselt number compartsons at $M_{2}=0.3$, no turbulence grid.

exit ideal dynamic pressure. The pressure distribution at each Mach number is for data obtained at a midrange Reynolds number. The variation in $C_{p}$ with Reynolds number at constant $M_{2}$ was found to be small, as was the variation in $C_{p}$ with surface roughness. On the suction surface $C_{p}$ shows a rapid increase; the rate of which decreases as the Mach number increases. At the maximum $C_{p}$ the static pressure is less than the vane row exit pressure. The adverse pressure gradient which follows assures that, even at low turbulence intensity, for most test cases the flow over the remainder of the suction surface will be turbulent. The adverse pressure gradient increases as the Mach number increases. The pressure surface has low velocities over the first $40 \%$ of the surface followed by strongly accelerating flow. The same analysis as is used here for the heat transfer predictions was used to compare predicted and experimental pressures for a smooth vane of the same geometry. Boyle et al.(1998) showed good agreement between predicted and measured $C_{p}$ for the smooth vane.

Heat transfer comparisons. Heat transfer is given in terms of Nusselt number, using $C_{\mathrm{x}}$ as the reference dimension, and the thermal conductivity at the inlet total temperature. Calculations were done with the same average gas-to-wall temperature ratio as for the data. Because the temperature differences were small, the Nusselt number was based on the difference between the surface and the local adiabatic recovery temperature. The local recovery temperature was determined from the local static pressure, the isentropic relationships, and a recovery factor of 0.9 .

For each test condition comparisons are shown using one of the three models. Because the roughness height is not known precisely, and to show the sensitivity of predicted heat transfer to variations in roughness, predictions are shown for a range of roughness heights. 
Under some conditions the sensitivity was high, while for other conditions the sensitivity was small. Predictions are shown in order of increasing Mach number. At each Mach number, heat transfer comparisons are made at various Reynolds numbers for low turbulence intensity, and are followed by predictions at the high turbulence intensity. Predictions are shown for the entire vane surface, not just those regions where heat transfer data were available. While eac $h$ test condition shows predictions for only a single model, successive comparisons use different models. In this way, the effects of different models can be compared for similar, though not identical test conditions. The three models used are identified as: (1) the Cebeci-Chang model, (2) the high Reynolds number $k-\omega$ model, ( $\mathrm{Hk} \omega)$, and (3) the low Reynolds number $k-\omega$ model,(Lkw).

Figure 5a shows comparisons for $M_{2}=0.3, R \epsilon_{2}=$ $0.041 \times 10^{6}$, and no grid using the Cebeci-Chang roughness model. The heat transfer at this test condition is most likely to resemble smooth vane heat transfer. At $s / C_{\mathrm{x}}$ near 2.6 on the suction surface, transition is seen in the data. Prior to this location, the transitioning analysis, which in reality is for laminar flow, is somewhat higher than the data. The transition model did not account for roughness, so the flow remained laminar. The predicted suction surface heat transfer nearly doubled when assuming fully turbulent flow from the leading edge. Even for an equivalent roughness height twice the expected equivalent height, the surface roughness is not large. This is expected, since at this Reynolds number the ratio of $h^{+} / h_{\mathrm{EQ}}$ is a minim um.

The experimental data, which were obtained from an infrared camera, are shown as up and down triangles. In the forward part of the vane, data from each camera view are indicated by different symbols. Moving from the leading edge at $s / C_{\mathrm{x}}=0.0$ to the pressure surface both the analysis and the data show a very rapid decrease in Nusselt number. The experimental data are shifted further along the pressure surface of the vane. This may be partially due to inaccuracies in mapping the camera view on to the vane surface. No adjustment was made in the mapped coordinates to achieve better positional agreement in the leading edge region. While this could be justified, the offsets seen in this and subsequent figures allow clearer comparisons between the data and analyses. In the leading edge region the experimental heat transfer is higher than predicted. The predicted stagnation point Frossling number is less than one, while, as expected the experimental value is close to one. In the analysis $h^{+}$varies in proportion to $y_{1}^{+}$. Near the leading edge $y_{1}^{+}$exceeded the suction surface value at $s / C_{\mathrm{x}}=2.6$, where the data show transition.
Figure 5b compares experimen tal Nusselt numbers with the Hkw predictions for the next highest Reynolds. Experimentally, suction surface transition moved forward with increased Reynolds number. This turbulence model shows smooth surface transition closer to the leading edge than the data. Increasing roughness, and thus the boundary value for $\omega$, moved the predicted transition location forward. Predicted Nusselt numbers are more sensitive to roughness variations than for the previous case. This is expected because $h^{+}$increases with Reynolds number for a given roughness height.

Data and predictions are shown for the Lkw turbulence model for $R e_{2}=0.101 \times 10^{6}$ in figure $5 \mathrm{c}$. Predictions are shown for inlet turbulence intensities of 3 and $5 \%$. The figure shows that transition occurred only for an inlet turbulence of $5 \%$, and $h_{\mathrm{EQ}} / C_{\mathrm{x}}=0.01$. No predictions are shown for the experimental inlet turbulence of $1 \%$. Steady state solutions were not obtained at experimental inlet turbulence levels due to oscillations caused by vortex shedding. There is poor agreement between the analysis and the data. In the leading edge region the analysis underpredicts the Nusselt numbers. On the suction surface the data show transition beginning at $s / C_{\mathrm{x}}$ close to 1.0 . The post transition $N u$ of about 300 is consistent for turbulent flow with the maximum level of 200 seen in figure $5 \mathrm{~b}$, for a $50 \%$ increase in Reynolds number.

Figure $5 \mathrm{~d}$ shows a second Nusselt number comparison using the Cebeci-Chang roughness model, assuming fully turbulent flow. Since the local values of $h^{+}$ are greater at the higher Reynolds number, the relative effects of surface roughness are also greater. The Cebeci-Chang model predicts the heat transfer in the leading edge region well, but underpredicts the effects of surface roughness on the rear portion of the suction surface. As in part (a) the fully turbulent analysis gives very high suction surface heat transfer near $s / C_{x}=0.5$. The data show rapidly increasing heat transfer prior to this location. However, the peak experimental value could not be determined, because the infrared camera could not see further along the suction surface.

The $\mathrm{Hk} \omega$ predictions are compared with data for the highest Reynolds number case at $M_{2}=0.3$ in figure 5e. The predicted effect of surface roughness on both the pressure and suction surfaces is large. The analysis agrees well with the data in the leading edge region, and for the rear of the suction surface. On the suction surface the prediction shows a rapid transition occurring close to the leading edge for the rough surface. The data indicate, however, that transition is not complete until $s / C_{\mathrm{x}}=2$. Even for the smooth surface, the analysis shows transition occurring closer to the leading edge than does the data. 


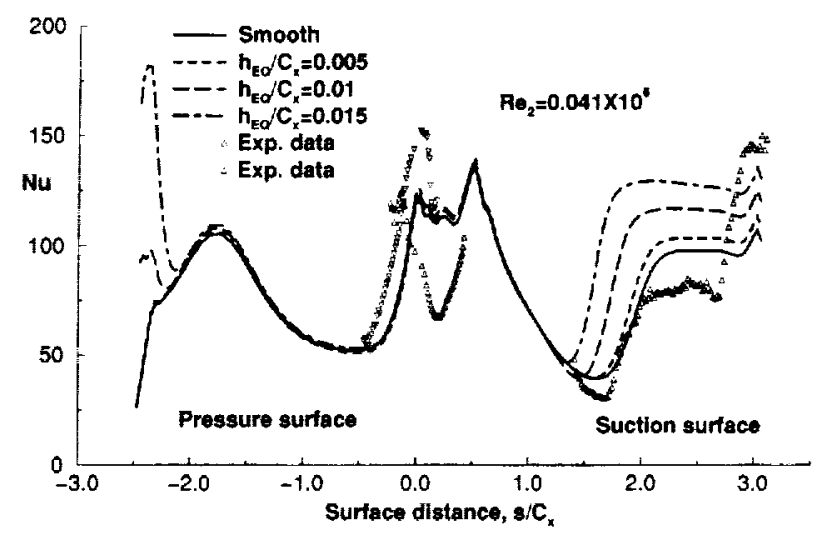

a) Comparison of Lk(i) results whith data.

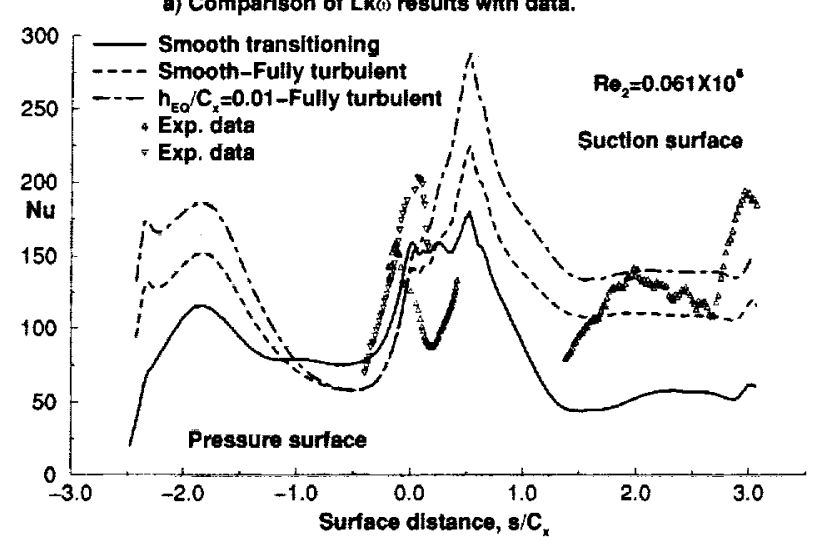

b) Comparison of Cebeci-Chang results with data.

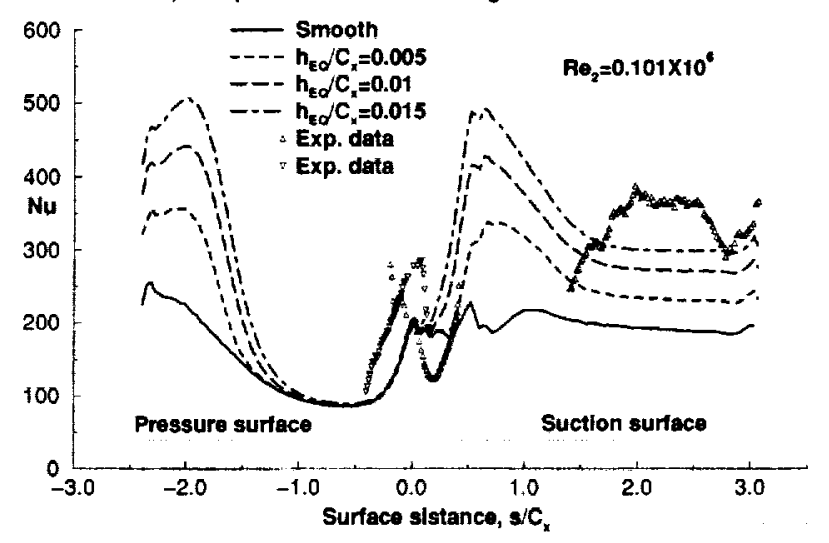

c) Comparison of Hk 13 results with data.

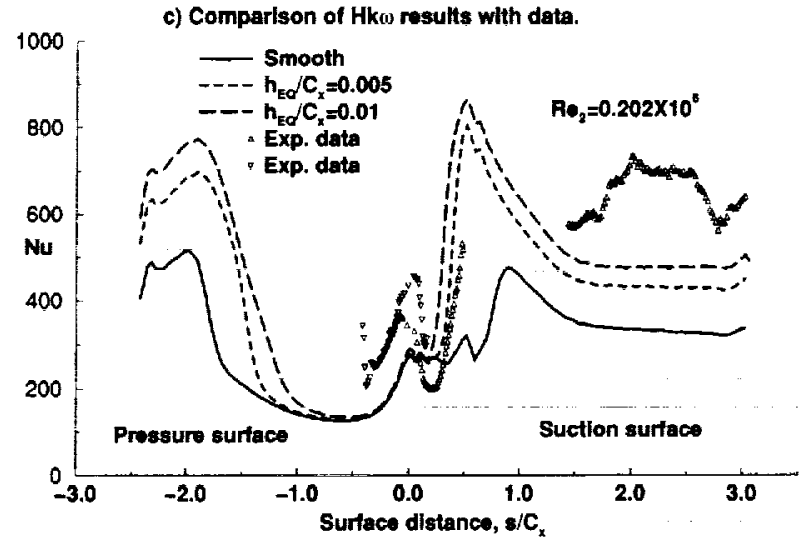

d) Comparison of Lko results whth data.

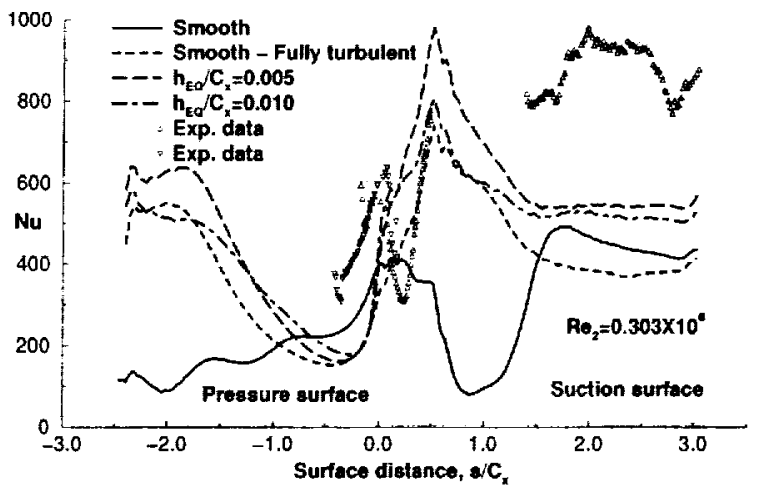

e) Comparison of Cebeci-Chang resulle with data.

Fig. 6 Nusselt number comparisone at $M_{2}=0.3$, turbulence grid.

Next, comparison with data are shown for the same exit Mach number, but for a higher turbulence level caused by the presence of the grid.

Figure 6a shows results for the lowest Reynolds number using the Lkw model. The influence of surface roughness on the predicted start of suction surface transition, and on the post transition Nusselt number level is clearly seen. The data show a two step transition process. However, Boyle et al.(2000) pointed out that at the lowest Reynolds number there is the possibility that, very close to the trailing edge, the Nusselt number is in error because heat loss across the thickness of the vane. This source of possible error decreases as the Reynolds number increases.

The Cebeci-Chang model predictions are compared with data in figure $6 \mathrm{~b}$ for the second lowest Reynolds number. In the leading edge region there is a significant difference in heat transfer between the two views. If the average of the two values from the two views is taken, the agreement in the overlap region is reasonably good. Since the estimated equivalent height ratio, $h_{\mathrm{EQ}} / C_{x}$ is 0.005 , the analysis agrees well with the experimental data for most of the rear portion of the suction surface. For the part of the pressure surface for which data are available, the analysis correctly predicts the rapid decrease in heat transfer moving away from the stagnation point.

Comparison with data for the middle Reynolds number are shown for the Hkw model in figure $6 \mathrm{c}$. The predictions are lower than the experimental data for the rear portion of the suction surface. At the leading edge the heat transfer level is well predicted based on the suction side data. Much of the suction side data show decreased heat transfer from the leading edge. A minimum is reached near $s / C_{x}=0.15$. Then the heat transfer increases rapidly. None of the analyses show 

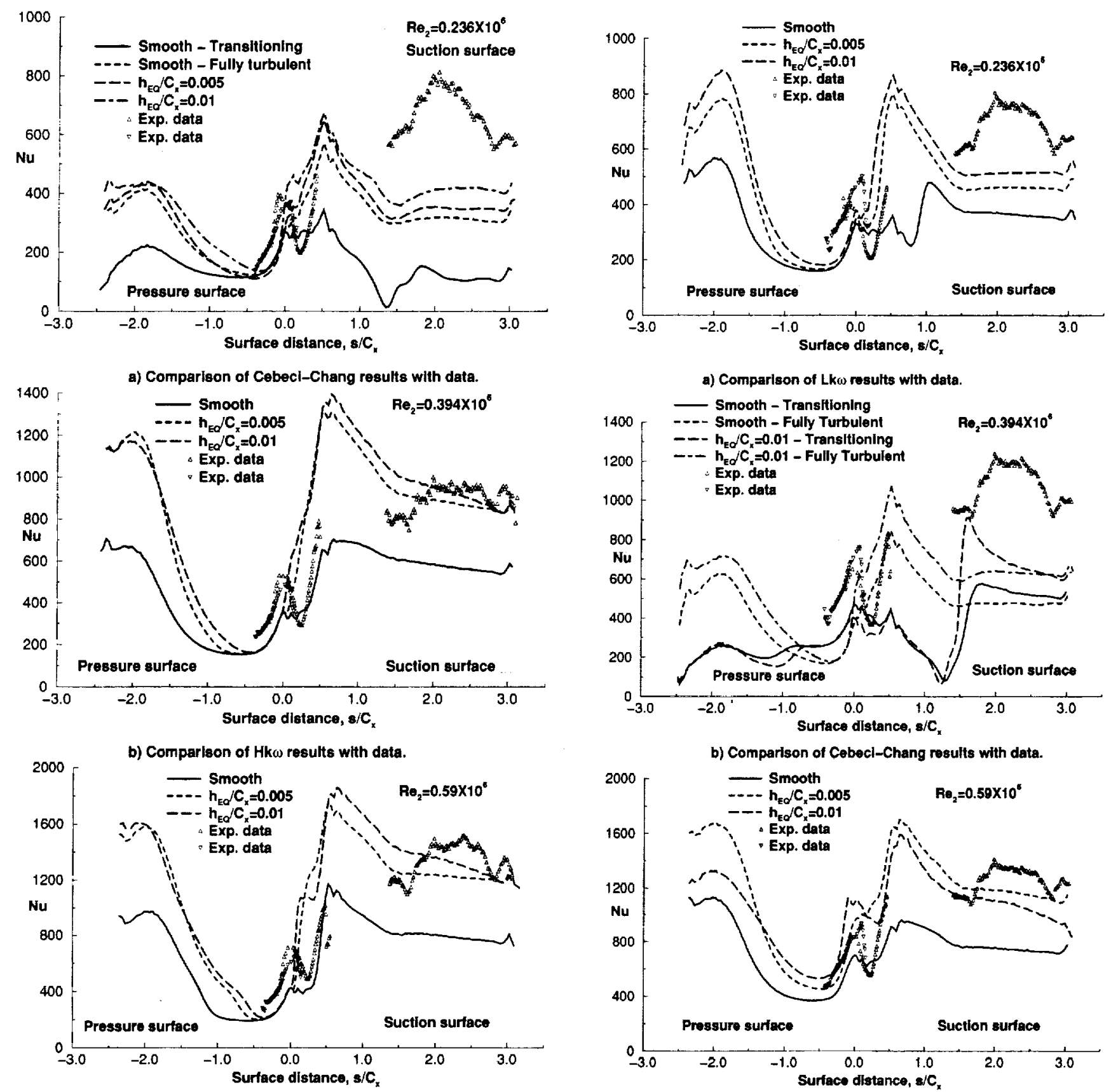

c) Comparison of $L k \omega$ results with data

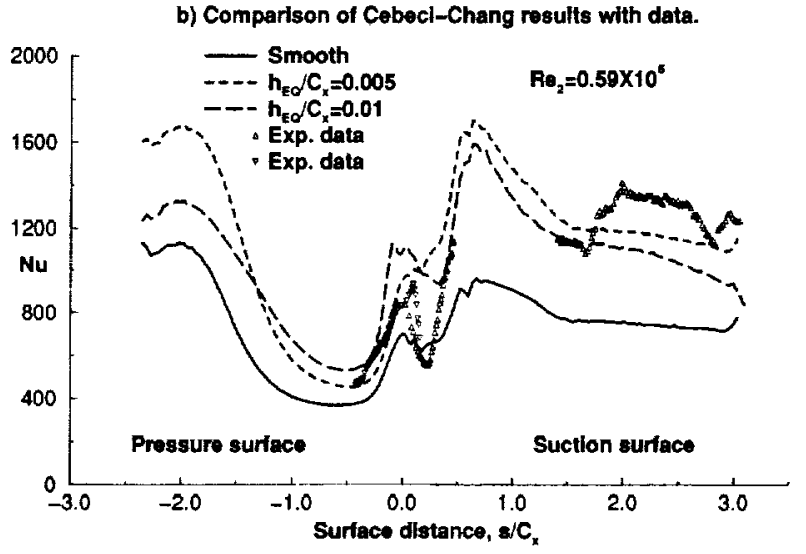

c) Comparison of Hk $\omega$ results with data

Fig. 7 Nusselt number comparisons, $\mathbf{M}_{2}=0.7$, no turbulence grid.

this suction surface trend. In the analyses the Nusselt number either remains fairly constant, or, at higher Reynolds numbers increases very rapidly after the stagnation point.

The Lkw predictions shown in figure $6 \mathrm{~d}$ are significantly lower than the data for the rear portion of the suction surface. The experimental heat transfer in the leading edge region is higher than the prediction. 
probably due to the increment in the mixing layer from roughness being only applied in the inner boundary layer region. For very high roughness, (in terms of $h^{+}$), this model may not give the appropriate increase in heat transfer with increasing roughness. This may also be true of the decrease in blade row efficiency with roughness. In terms of the predictions, the largest effect of roughness was to cause fully turbulent flow. The increased heat transfer on both suction and pressure surfaces due to assuming fully turbulent flow was greater than the increase due to surface roughness.

Raising the exit Mach number from 0.3 to 0.7 caused a large increase in the minim um exit Reynolds number. In addition to more than doubling the exit velocity, the minim um inlet total pressure increased. Consequently, the minimum $R e_{2}$ at $M_{2}=0.7$ was nearly six times greater than the minimum $R \epsilon_{2}$ at $M_{2}=0.3$, and was $80 \%$ of the maxim um $R e_{2}$ at $M_{2}=0.3$.

Figure 7 a compares experimen tal and predicted Nusselt numbers for the lowest Reynolds number tested at $M_{2}=0.7$. These results are for the no grid case, and show the Cebeci-Chang predictions. If Mach number did not affect the heat transfer, it is expected that the experimental data would be nearly the average of that shown in figures $5 \mathrm{~d}$ and $5 \mathrm{e}$. In the leading edge region, where the local Mach number is low, this is seen to be true. However, on the rear portion of the suction surface, where the local Mach number is close to the exit value, the variation of Nusselt number with surface distance is different. The higher Mach number data in figure $7 \mathrm{a}$ show a more negative slope over the rear portion of the suction surface. Figure 7a shows that the analysis agrees well with the data in the leading edge region. However, it is much lower than the measuremen ts for the rear of the suction surface.

Figures $7 \mathrm{~b}$ and $i c$ show comparisons with data for the two versions of the $k-\omega$ model. In the leading edge region, both models show satisfactory agreement. On the rear of the suction surface both models are in relatively good agreement with the data. The $H k \omega$ model appears to have somewhat better agreement. However, both models agree with the data to the same degree. Either turbulence model, when compared with the other Reynolds number data, showed the same degree of agreement with the data. The results in these two figures also illustrate that continually increasing the roughness height results in only small changes in the predicted heat transfer.

Comparing the results in figures 7 and 8 show the effect of an increased turbulence level. There is no consistent experimental heat transfer variation with turbulence intensity for the rear of the suction surface.
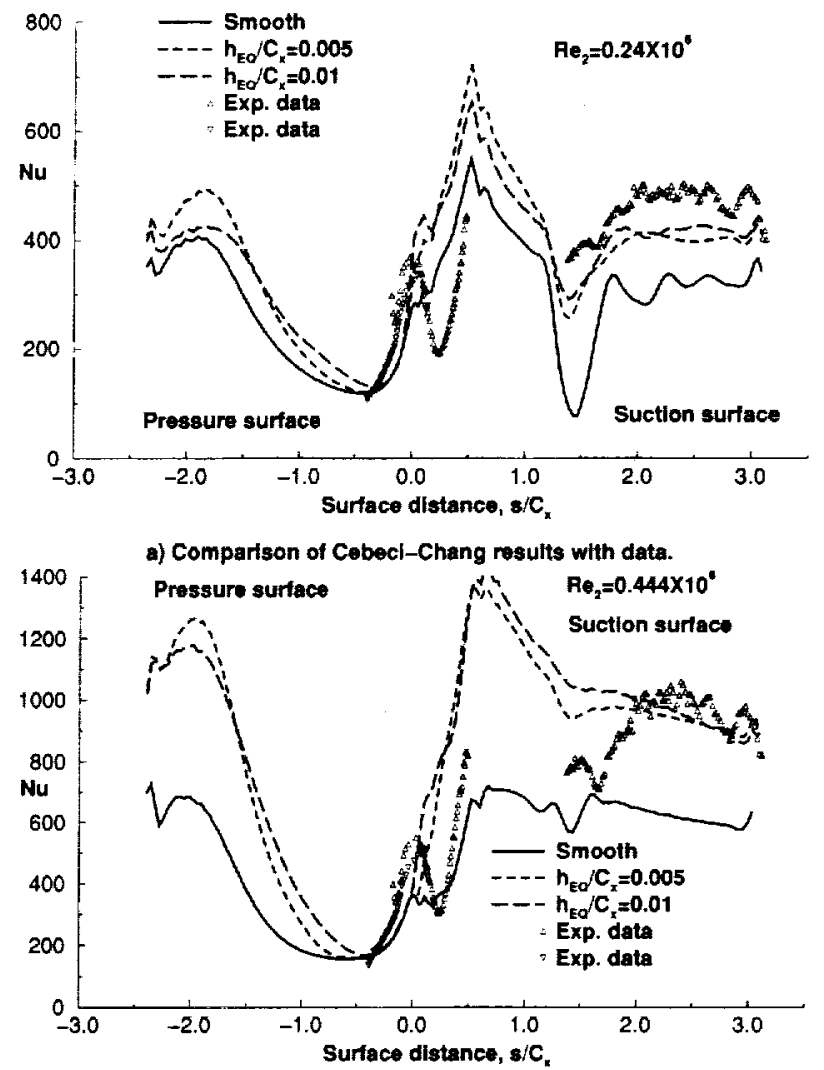

b) Comparison of Hkw results with data.

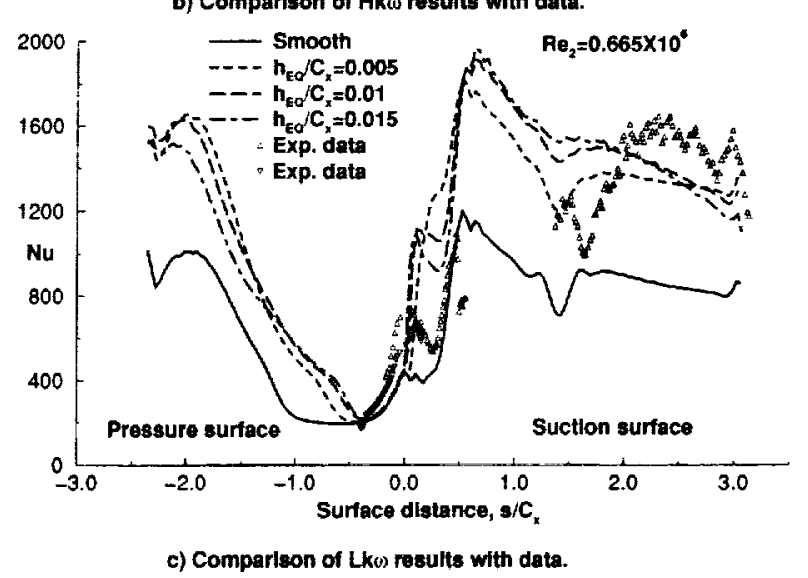

Fig. 9 Nusselt number compartsons, $M_{2}=0.9$, no turbulence grid.

But, the variation is small; within the measurement uncertainty at each Reynolds number. In the leading edge region the variation is more consistent, and shows a heat transfer increase with higher turbulence intensity.

Comparing predictions to each other for the cases presented in figures 7 and 8 illuminate differences among the turbulence models. The Cebeci-Chang model shows a smaller increase in heat transfer with roughness than do either of the two $k-\omega$ models. The $\mathrm{Hkw}$ model is in good agreement with the measured 


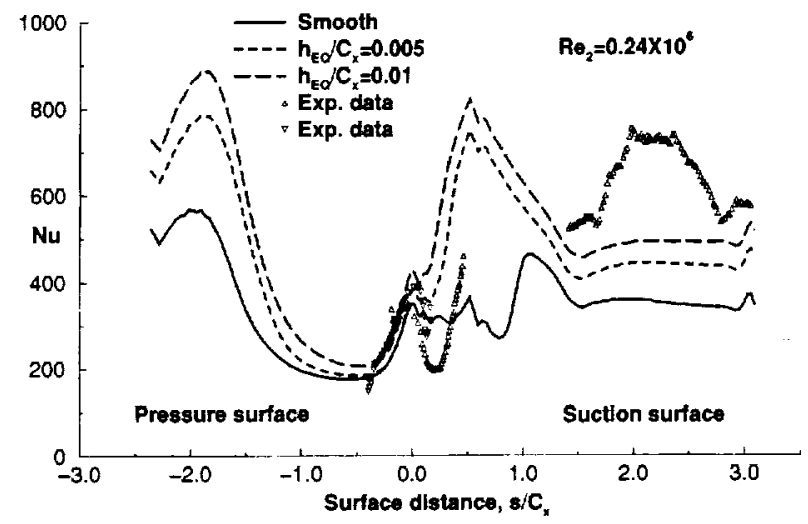

a) Comparison of $L k \omega$ results with data.

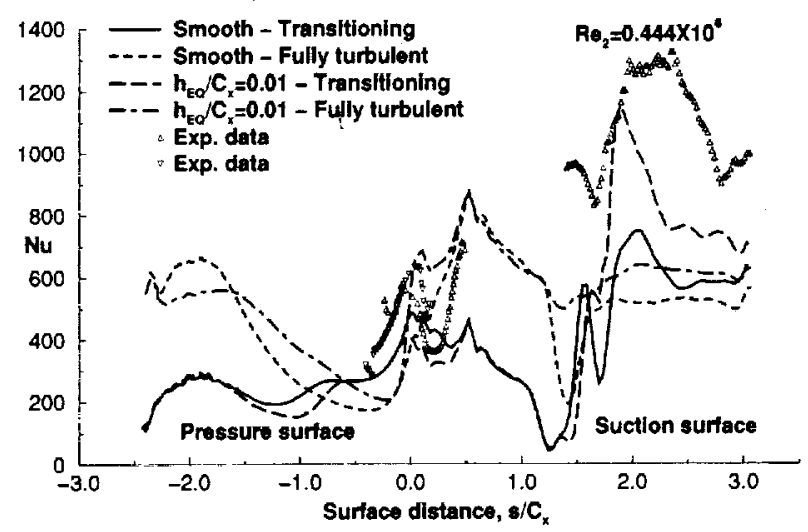

b) Comparison of Cebeci-Chang results with data.

heat transfer for the rear of the suction surface. Figure 8 , and to a lesser extent figure 7, show that for the forward portion of the vane, on either side of the leading edge, all models agree reasonably well with the data. This occurs when, in the overlap region, the average from the two views is used.

The results shown in figure $8 \mathrm{c}$ illustrate a difficulty that was observed with the $\mathrm{Hk} \omega$ model. The predictions show a maxim um Nusselt number at an intermediate roughness height. This was surprising, and the cause for this was found to be sensitivity of the HKw model to the near-wall grid line spacing.

Lastly, comparisons are shown in figures 9 and 10 for $M_{2}=0.9$. The percentage change in exit Reynolds number is not as great as the the percentage change in exit Mach number. At high Mach numbers density decreases with increasing Mach number, resulting in smaller Reynolds number changes. Comparing results in figures 7 and 9 show the effect of a Mach number variation for no grid-low turbulence cases. Comparisons between figures 8 and 10 show the Mach number effects for high turbulence.
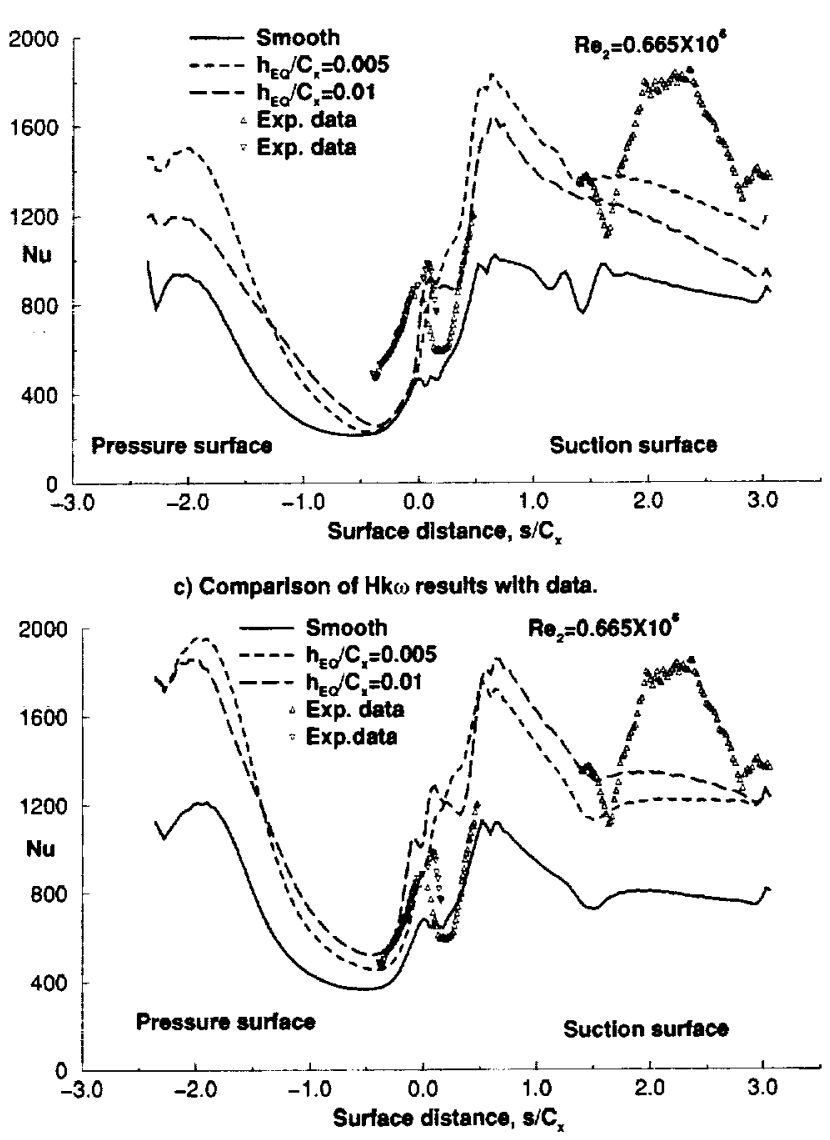

d) Comparison of Lk $\omega$ results with data.

Fig. 10 Nusselt number comparisons for $M_{2}=0.9$, turbulence grid.

The smooth surface results for fully turbulent flow in figure $9 \mathrm{a}$ show a sharp decrease in suction surface Nusselt number beginning at $s / C_{\mathrm{x}}=1$. While this was seen to some extent for the transitioning prediction in figure $7 \mathrm{a}$, it was not seen for the comparable fully turbulent prediction. Figure 4 shows that the adverse suction surface pressure gradient is steeper for the higher exit Mach number. The steeper gradient leads to a more rapid thickening of the boundary layer, leading to the decrease in heat transfer. Although not shown in the figures, the two $k-\omega$ model results showed similar Nusselt number behavior to that seen in figure $9 \mathrm{a}$ for the algebraic model. The magnitude of the dip in heat transfer, however, was less for both $k-\omega$ models. The dip in heat transfer is less when the analyses are for a rough surface. The experimental data in figure 9 also exhibit this behavior, but so do the data in figure 7 . 
Table III. Summary of rotor test conditions.

\begin{tabular}{|c|c|c|}
\hline & \multicolumn{2}{|c|}{ Ideal Axial chord Re No. $\times 10^{-6}$} \\
\hline$\beta_{\text {IN }}$ & Inlet & Exit \\
\hline 50 & 0.37 & 0.56 \\
& 0.28 & 0.42 \\
\hline 36 & 0.23 & 0.42 \\
& 0.12 & 0.23 \\
\hline
\end{tabular}

In the leading edge region figure 9 shows that, for all three Reynolds numbers, the analysis agrees reasonably well with the data. There appears to be little reason to prefer one turbulence model over the other based on the data in this figure alone.

The comparisons in figure 10 for $M_{2}=0.9$ show results very similar to those in figure 8 for $M_{2}=0.7$. It was found that, of the two $k-\omega$ turbulence models, the model without a low Reynolds number effect (the Hkw model), was more sensitive to near wall spacing than was the Lkw model. Even though the grid had a near wall spacing of $y_{1}^{+}=1$ or less, the Hkw model results changed when the near wall spacing was reduced. The HKw predictions for the highest Reynolds number case shown in figure $10 \mathrm{c}$ became almost identical to those shown in figure $10 \mathrm{~d}$ for the $L k \omega$ model when the near wall grid spacing was reduced. The $L k \omega$ model and the Cebeci-Chang model heat transfer predictions did not change with reduced near wall spacing.

The term $\omega_{\text {IN }}$ used as part of the criteria for determining $\omega_{0}$ is not part of the standard $k-\omega$ turbulence model, Wilco x(1994). It is most likly to have an influence at high Reynolds numbers and high turbulence intensities. For the cases examined in this study, omitting $\omega_{\text {IN }}$ from the criteria for determining $\omega_{0}$ did not affect the heat transfer predictions.

\section{Rotor blade results}

Blair(1994) presented both full span and midspan rotor heat transfer distributions at different Reynolds numbers and incident flow angles. Measurements were made for both a rough and smooth blade. In con trast to the stator data, these rotor blade data had measurement over the entire surface. Table III describes the test conditions for which comparisons are made.. For the rough surface a screened grit of $0.055 \mathrm{~mm}$ was applied to the surface. This grit size is 0.0041 when normalized by the reference chord, $C_{x}$. Additional information regarding the roughness height was not available. Roughness calculations were done using multiples of this height. A value of $h_{\mathrm{EQ}} / C_{x}=0.0041$ corresponds to an equivalent height-to- RMS value, $h_{\mathrm{EQ}} / h_{\mathrm{RMS}}$, of approximately two.

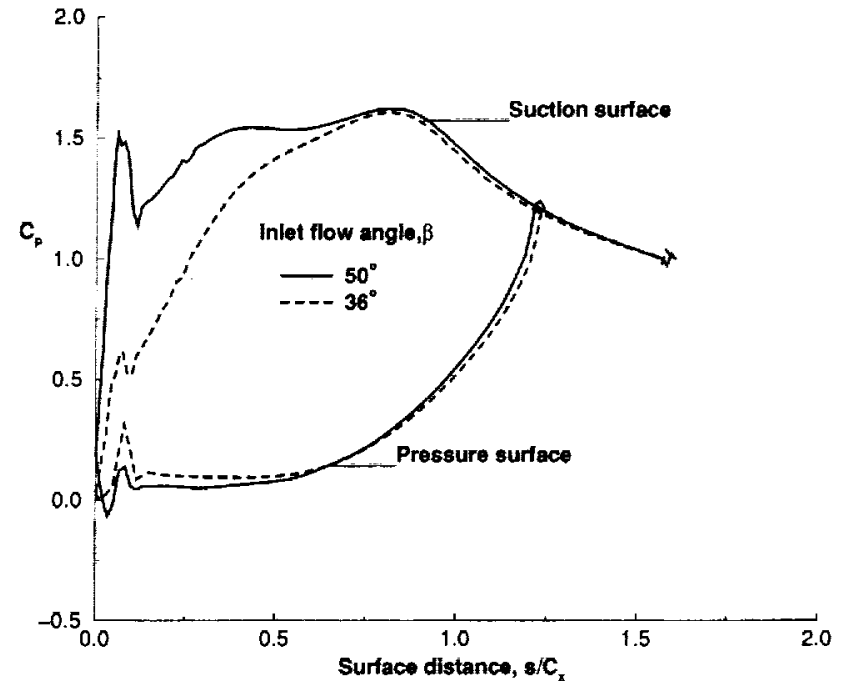

Fig. 11 Predicted pressure coefficlent for rotor of Blair(1994).

The pressure coefficient distributions are shown in figure 11 for the two inlet flow angles. At the higher inlet flow angle of 50 degrees there is an overspeed close to the leading edge of the suction surface. This causes rapid transition. At this inlet angle the suction surface will be almost completely turbulent. At the lower inlet flow angle of 36 degrees, there is less flow turning. Consequently, the pressure difference across the rotor is less. At this inlet angle the flow accelerates more uniformly The smooth surface boundary layer remains laminar until the peak pressure coefficient, $C_{P}$, is reached at $s / C_{x}$ of approximately 0.9 .

At an inlet angle of 50 degrees, the pressure surface velocities are very low for nearly the first half of the surface distance. This is followed by a strong acceleration. The smooth surface pressure surface boundary is likely to be laminar, especially at the lower Reynolds number. For an inlet angle of 36 degrees, there is a pressure surface overspeed. Unless the flow relaminarizes, the pressure surface boundary layer will be turbulent.

Figure 12 compares measured and predicted Nusselt numbers for the rotor at the four test conditions. In each case two rough surface predictions are shown. They are for roughness height ratios. $h_{\mathrm{EQ}} / C_{x}$ of 0.004 and 0.008 . The two values shown illustrate the sensitivity of the predictions to roughness height. The higher value represents an estimated upper bound on the roughness height.

The comparisons in figure $12 \mathrm{a}$ are for $\beta_{\mathrm{IN}}=50^{\circ}$; and an exit Reynolds number of $0.56 \times 10^{6}$ using the $\mathrm{H} k \omega$ model. The agreement with both the rough and smooth surface data is good for almost the en tire rotor 

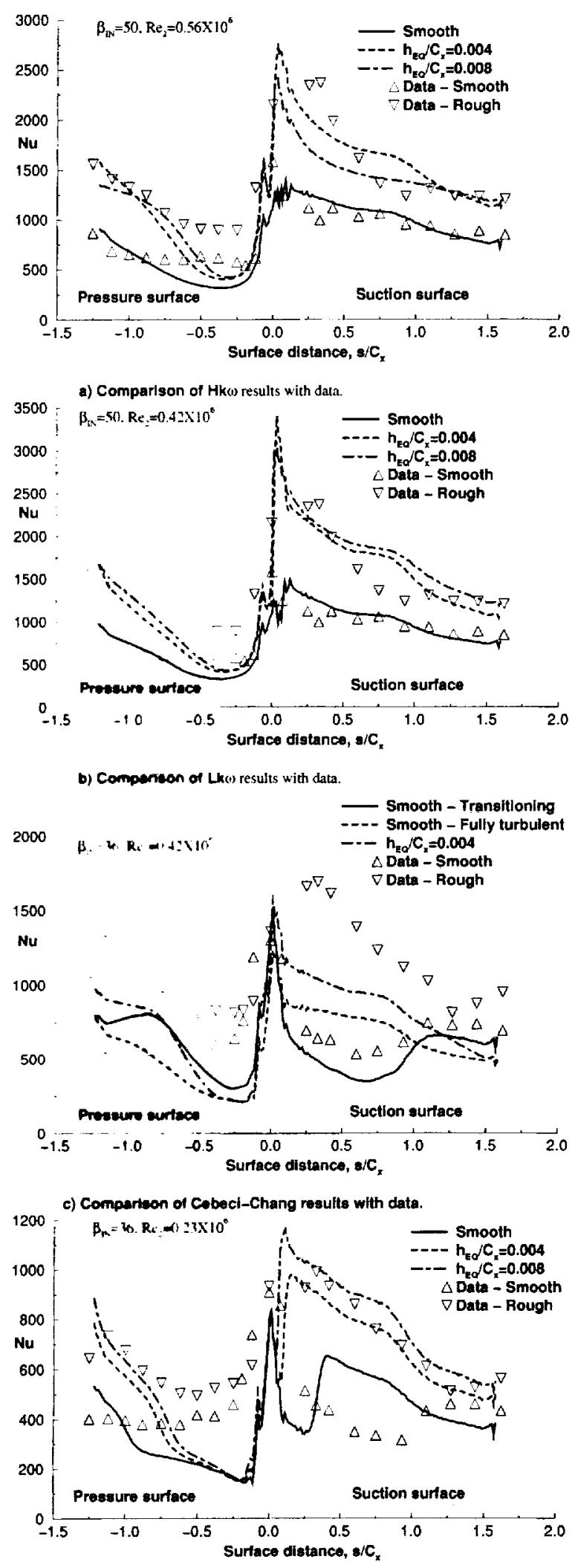

d) Comparison of Lko results with data. surfaces. Only for the first third of the pressure surface does the analysis underpredict the rough surface heat transfer data. Here again, the Hkw model shows decreased suction surface heat transfer with increased roughness.

The predictions shown in figure $12 \mathrm{~b}$ are for the $\mathrm{L} k \omega$ model. The results are for the lower Reynolds number, but still at the design inlet flow angle. The agreement with data is good for both the smooth and rough surfaces. The predictions are lower than the rough surface data for the forward portion of the pressure surface, and high than the data midway along the suction surface. The Lkw model shows increased heat transfer as the surface roughness roughness is doubled. This is in contrast to the $\mathrm{H} k w$ model results shown in figure $12 \mathrm{a}$.

The analysis does not agree as well with the data for the two off-design inlet flow angle cases. The Cebeci-Chang model results shown in figure $12 \mathrm{c}$ underpredict the effect of roughness. At a roughness height, $h_{\mathrm{EQ}} / C_{\boldsymbol{x}}=0.004$ the Cebeci-Chang model shows a significant increase due to roughness in predicted suction surface heat transfer. However, the model predicts almost the same heat transfer as for a smooth surface, when the roughness height is doubled. This suprising result is consistent with the heat transfer results obtained using this model for the stator vane. At high $h^{+}$ values, this model showed a peak in surface heat transfer, as the roughness height increased. The analysis is in reasonably good agreement with the smooth surface data for the suction surface. However, it underpredicts the pressure surface heat transfer close to the leading edge, and overpredicts the heat transfer closer to the trailing edge. The smooth surface transitioning model gives higher heat transfer over much of the pressure surface, than does the fully turbulent analysis. This occurs because the transitional model augmen ts the eddy viscosity in the laminar region to account for freestream turbulence effects. The fully turbulent model does not augment the eddy viscosity to account for freestream turbulence effects.

The Lkw model results shown in figure $12 \mathrm{~d}$ for the lower Reynolds number show that for the suction surface this model accurately predicts heat transfer for the rough surface. Only for the rear half of the pressure surface does this model agree with the experimental rough surface data. The results for the forward half of the pressure surface are similar to those shown in figure $12 \mathrm{a}$ for the design inlet flow angle. However, the degree of agreement with data is poorer for the lower inlet flow angle. For the smooth surface the $\mathrm{L} k \omega$ model predicts suction surface transition before it is seen in the data.

Fig. 12 Comparisons with data of Blair(1994) . 
Figure $12 \mathrm{c}$ shows that the transition model used with the algebraic turbulence model gives better agreement with the smooth blade data.

Overall, the results for the rotor blade comparisons show the same trends as for the stator vane. Where roughness causes transition close to the leading edge, the $\mathrm{H} k \omega$ model gave best agreement with data. If the momentum thickness Reynolds numbers were high enough to cause smooth surface transition close to the leading edge, the $\mathrm{L} k w$ model gave good agreement for roughness effects. The Cebeci-Chang roughness modeI, while it does show increased heat transfer for rough surfaces, underpredicts the effects of surface roughness.

\section{CONCLUSIONS}

The primary conclusion of this work is that the high Reynolds number formulatian of the $k-\omega$ turbulence model results in the best agreement with the experimental data. It is best in the sense that it provides a conservative estimate for the effect of roughness on heat transfer. The high Reynolds number formulation gave early transition at moderate Reynolds numbers and low turbulence intensities. This was consistent with the experimental results. The low Reynolds number formulation showed transition like behavior at low turbulence intensities, which was inconsistent with the data.

Predictions made using the Cebeci-Chang turbulence model showed a heat transfer increase with roughness. When this model $w$ as used for a rongh surface, the flow was assumed to be fully turbulent. This approach resulted in better agreement with the data than the low Reynolds number formulation of the $k-\omega$ turbulence model. The heat transfer increase due to roughness was less with the Cebeci-Chang model than with the high Reynolds number $k-\omega$ model. Comparisons with the data showed the high Reynolds number $k-\omega$ predictions agreed better than the Cebeci-Chang model at higher Reynolds numbers. This is consistent with the observations of Boyle and Civinskas(1991). They reported lower than measured heat transfer for some test. cases using the Cebeci-Chang roughness model.-

The choice of model for rough surface heat transfer predictions is strongly influenced by accurate knowledge of the equivalent roughness height. In addition to the variation in roughness height at various surface locations, there was a large variation in equivalent height among various models for predicting the equivalent height. Reducing the variation among correlations for equivalent height is as important as improving the turbulence model for rough surface heat transfer predictions.

\section{REFERENCES}

Abuaf, N., Bunker, R.S., and Lee, C.P., 1997, "Effects of Surface Roughness on Heat Transfer and Acrodynamic Performance of Turbine Airfoils," ASME paper 9T-GT-10.

Arnone, A., Lion, M.-S., and Povinelli, L.A., 1992, "NavierStokes Solution of Transonic Cascade Flows Using NonPeriodic C-Type Grids," AIAA Journal of Propulsion and Power, Vol. 8, No. 2, pp. 410-417.

Baldwin, B.S., and Lomax, H., 1978, "Thin-Layer Approximation and Algebraic Model for Separated Turbulent Flows," AIA A paper $78-257$.

Bammert, K., and Stanstede, H., 1972, "Measurements Concerning the Influence of Surface Roughness and Profile Changes on the Performance of Gas Turbines," ASME Journal of Engineering for Power, Vol. 94, pp. 20T-213.

Bammert, K., and Stanstede, H., 1976, "Influences of Manufacturing Tolerances and Surface Roughness of Blades on the Performance of Turbines," ASME Journal of Engineering for Power, Vol. 98, pp. 29-36.

Blair, M.F., 1994, "An Experimental Study of Heat Transfer in a Large-Scale Turbine Rotor Passage," ASME Journal of Turbomachinery, Vol. 116, pp. 1-13.

Boyle, R.J., Spuckler, C.M., Lucci, B.L., and Camperchioli, W.P., 2000, "Infrared Low Temperature Turbine Vane Rough Surface Heat Transfer Measurements," ASME paper $2000-G T-0216$.

Boyle, R.J., Lucci, B.L., Verhoff, V.G., Camperchioli, W.P., and La, H., 1998, "Aerodynamics of a Transitioning Turbine Stator Over a Range of Reynolds Numbers," ASME paper 98-GT-285.

Boyle, R.J., and Civinskas, K.C., 1991, "Two-Dimensional Navier- Stokes Heat Transfer Analysis for Rough Turbine Blades," AIAA paper AIAA-91-2129.

Boynton, J.L., Tabibzadeh, R., and Hudson, S.T., 1992, "Investigation of Rotor Blade Roughness Effects on Turbine Performance," ASME Journal of Turbomachinery, Vol. 115, pp. 614-620.

Cebeci, T., and Chang, K.C., 1978, "Calculation of Incompressible Rough-Wall Boundary-Layer Flows," AIAA Journal, Vol. 16, No. 7, pp 730-735.

Chima, R.V., 1987 "Explicit Multigrid Algorithm for QuasiThree- Dimensional Flows_in Turbomachinery." AIAA Journal of Propulsion and Power, Vol. 3, No. 5, pp. 397-405.

Chima, R.V., and Yokota, J.W., 1988, "Numerical Analysis of Three-Dimensional Viscous Internal Flows," AIAA paper 88-3522, (NASA TM-100878).

Chima, R.V., Giel, P.W., and Boyle, R.J., 1993, "An Algebraic Turbulence Model for Three-Dimensional Viscous Flows," AIAA paper 93-0083, (NASA TM-105931). 
Chima, R.V., 1996, "Application of the $k-\omega$ Turbulence Model to Quasi-Three-Dimensional T urbomachinery Flows," AIAA Journal of Propulsion and Power, Vol. 12, No. 6, pp. 1176-1179.

Dagnall, H., 1986, "Exploring Surface Texture," Second ed., Rank Taylor Hobson Limited, Leicester, England, p 158 .

Dirling, R.B., 1973, "A Method for Computing Roughwall Heat Transfer Rates on Re-Entry Nosetips," AIAA paper $73-763$

Dunn, M.G., Kim, J., Civinsk as, K.C., and Boyle, R.J., 1994, "Time-Averaged Heat Transfer and Pressure Measuremen ts and Comparison with Prediction for a Two-Stage Turbine. ASME Journal of Turbomachinery, Vol. 116, pp. 14-22.

Dvorak, F.A., 1969, "Calculation of Turbulent Boundary Layers on Rough Surfaces in Pressure Gradient," AIAA Journal, Vol. 7, No. 9, pp 1752-1759.

Kind, R.J., Serjak, P.J., and Abbott, M.W.P ., 1998, "Measuremen ts and Prediction of the Effects of Surface Roughness on Profile Losses and Deviation in a Turbine Cascade," ASME Journal of Turbomachinery, Vol. 120, pp. $20-27$.
Sigal, A., and Danberg. J.E., 1990, "New Correlation of Roughness Density Effect on the Turbulent Boundary Layer," AIAA Journal, Vol. 28, No. 3, pp 554-556.

Tarada, F., 1990, "Prediction of Rough W all Boundary Layers Using a Low Reynolds Number $k-\epsilon$ Turbulence Model," Int. J. of Heat and Fluid Flow, Vol. 11, pp 331-345.

Tarada, F., and Suzuki, M., 1993, "External Heat Transfer Enhancement to Turbine Blading Due to Surface Roughness," ASME paper 93-GT-74.

Taylor, R.P., Coleman, H.W., and Hodge, B.K., 1985, "Prediction of Turbulent Rough-W all Skin Friction Using a Discrete Element Approach," ASME Journal of Fluids Engincering. Vol. 107 pp 251-257.

Tolpadi, A.K, and Crawford, M.E., 1998, "Predictions of the Effect of Roughness on Heat Transfer From Turbine Airfoils," ASME paper 98-GT-087.

W aigh, D.R., and Kind, R.J., 1998, "Improved Aerodynamic Characterization of Regular Three-Dimensional Roughness," AIAA Journal, Vol. 36, No. 6, pp 11171119 .

Wilcox, D.C., 1994, Turbulence Modeling for CFD, DCW Industries, Inc., La Canada, CA. 


\section{REPORT DOCUMENTATION PAGE}

Form Approved

OMB No. 0704-0188

Public reporting burden for this collection of information is estimated to average 1 hour per response, Including the time for reviewing instructions, searching existing data sources, gathering and mainfaining the data needed, and completing and revlewing the collectlon of intormath. Send comments regardmg this burden estimate or any other aspect of this

Davis Highway. Suite 1204, Artington, VA 22202-4302, and to the Office of Management and Budget, Paperwork Reduction Project (0704-018B), Washington, DC 20503.

\begin{tabular}{l|l|l|} 
1. AGENCY USE ONLY (Leave blank) & 2. REPORT DATE & 3. REPORT TYPE AND DATES COVERED
\end{tabular}

December 2000

Technical Memorandum

4. TITLE AND SUBTITLE

5. FUNDING NUMBEAS

Comparison of Predicted and Measured Turbine Vane Rough

Surface Heat Transfer

6. AUTHOR(S)

WU-708-28-13-00

R.J. Boyle, C.M. Spuckler, and B.L. Lucci

7. PERFORMING ORGANIZATION NAME(S) AND ADDRESS(ES)

National Aeronautics and Space Administration

John H. Glenn Research Center at Lewis Field

Cleveland, Ohio 44135-3191

8. PERFORMING ORGANIZATION REPORT NUMBER

E-12338

9. SPONSORINGMONITORING AGENCY NAME(S) AND ADDRESS(ES)

10. SPONSORING/MONITORING AGENCY REPORT NUMBER

National Aeronautics and Space Administration

Washington. DC 20546-0001

NASA TM-2000-210219

$2000-\mathrm{GT}-0217$

11. SUPPLEMENTARY NOTES

Prepared for the 45th International Gas Turbine and Aeroengine Technical Congress sponsored by the American Society of Mcchanical Engineers, Munich, Germany, May 5-8, 2000. Responsible person, R.J. Boyle, organization code 5820, $216-4.33-5889$

\begin{tabular}{l|l} 
12a. DISTRIBUTIONAVAILABILITY STATEMENT & 12b. DISTRIBUTION CODE
\end{tabular}

Unclassified-Unlimited

Subject Category: 34

Distribution: Nonstandard

Available clectronically at htp://gltrs,grc.nasa.gov/GLTRS

This publication is available from the NASA Center for AeroSpace Information, 301-621-0390.

13. ABSTRACT (Maximum 200 words)

The proposed paper compares predicted turbine vane heat transfer for a rough surface over a wide range of test conditions with experimental data. Predictions were made for the entire vane surface. However, measurements were made only over the suction surface of the vane, and the leading edge region of the pressure surface. Comparisons are shown for a wide range of test conditions. Inlet pressures varied between 3 and 15 psia, and exit Mach numbers ranged between 0.3 and 0.9 . Thus, while a single roughened vane was used for the tests, the effective rougness, $\left(k^{+}\right)$, varied by more than a factor of ten. Results were obtained for freestream turbulence levels of 1 and 10 percent. Heat transfer predictions were obtained using the Navier-Stokes computer code RVCQ3D. Two turbulence models, suitable for rough surface analysis, are incorporated in this code. The Cebeci-Chang roughness model is part of the algebraic turbulence model. The $k-\omega$ turbulence model accounts for the effect of roughness in the application of the boundary condition. Roughness causes turbulent flow over the vane surface. Even after accounting for transition, surface roughness significantly increased heat transfer compared to a smooth surface. The $k-\omega$ results agreed better with the data than the Cebeci-Chang model. However, the low Reynolds number $k-\omega$ model did not accurately account for roughness when the freestream turbulence level was low. The high Reynolds number version of this model was more suitable when the freestream turbulence was low.

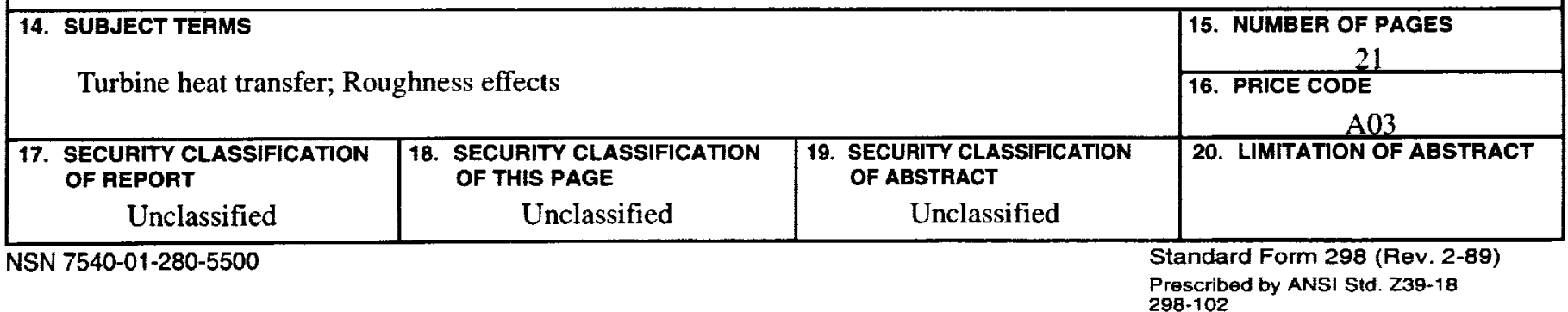

